\title{
Cell cycle control of septin ring dynamics in the budding yeast
}

\author{
Víctor J. Cid, ${ }^{1}$ Lubica Adamiková, ${ }^{2}$ Miguel Sánchez, ${ }^{3}$ María Molina ${ }^{1}$ \\ and César Nombela ${ }^{1}$
}

Author for correspondence: María Molina. Tel: +34 91 3941748. Fax: +34913941745.

e-mail: molmifa@eucmax.sim.ucm.es

\footnotetext{
1 Departamento de Microbiología II, Facultad de Farmacia, Universidad Complutense, 28040Madrid, Spain

2 Department of Biochemistry, Comenius University, Faculty of Natural Sciences, Mlynská dolina $\mathrm{CH}-1,84215$ Bratislava, Slovakia

3 Departamento de Biología y Genética. Edificio Departamental, Campus Miguel de Unamuno, Universidad de Salamanca, 37007, Salamanca, Spain
}

\begin{abstract}
Septins constitute a cytoskeletal structure that is conserved in eukaryotes. In Saccharomyces cerevisiae, the Cdc3, Cdc10, Cdc11, Cdc12 and Shs1/Sep7 septins assemble as a ring that marks the cytokinetic plane throughout the budding cycle. This structure participates in different aspects of morphogenesis, such as selection of cell polarity, localization of chitin synthesis, the switch from hyperpolar to isotropic bud growth after bud emergence and the spatial regulation of septation. The septin cytoskeleton assembles at the pre-bud site before bud emergence, remains there during bud growth and duplicates at late mitosis eventually disappearing after cell separation. Using a septin-GFP fusion and time-lapse confocal microscopy, we have determined that septin dynamics are maintained in budding zygotes and during unipolar synchronous growth in pseudohyphae. By means of specific cell cycle arrests and deregulation of cell cycle controls we show that septin assembly is dependent on G1 cyclin/Cdc28mediated cell cycle signals and that the small GTPase Cdc42, but not Rho1, are essential for this event. However, during bud growth, the septin ring shapes a bud-neck-spanning structure that is unaffected by failures in the regulation of mitosis, such as activation of the DNA repair or spindle assembly checkpoints or inactivation of the anaphase-promoting complex (APC). At the end of the cell cycle, the splitting of the ring into two independent structures depends on the function of the mitotic exit network in which the protein phosphatase Cdc14 participates. Our data support a role of cell cycle control mechanisms in the regulation of septin dynamics to accurately coordinate morphogenesis throughout the budding process in yeast.
\end{abstract}

Keywords: GFP, morphogenesis, Saccharomyces cerevisiae

\section{INTRODUCTION}

Septins, originally found in yeast, constitute a novel family of structural proteins that assemble as microfilaments in many eukaryotic cells, from yeast to mammals (Longtine et al., 1996; Field \& Kellogg, 1999). Mutations in septin-encoding genes have been reported to cause cytokinetic defects in the budding yeast (Hartwell, 1971; Hartwell et al., 1974; Slater et al., 1985; Cid et al., 1998a). Homologous proteins from flies (Drosophila melanogaster; Neufeld \& Rubin, 1994; Fares et al., 1995) and mice (Kinoshita et al., 1997) have also been related to cytokinetic functions, while a human

Abbreviations: APC, anaphase-promoting complex; CDK, cell-cycle-dependent kinase. homologue has been reported to play a role in secretion in neurons (Beites et al., 1999). In Saccharomyces cerevisiae, seven septin homologues exist. Five of them assemble in an interdependent fashion at the motherbud constriction during the mitotic cycle, namely Cdc3, Cdc10, Cdc11, Cdc12 and Sep7/Shs1 (Haarer \& Pringle, 1987; Kim et al., 1991; Ford \& Pringle, 1991; Cid et al., 1998a; Carroll et al., 1998; Mino et al., 1998). Another two are specifically expressed in the sporulation developmental programme (Spr3 and Spr28; De Virgilio et al., 1996; Fares et al., 1996). The yeast mitotic septins have been reported to form long filaments in vitro (Frazier et al., 1998), supporting the idea that they might form heterocomplexes in vivo to constitute the $10 \mathrm{~nm}$ microfilaments at the mother-daughter constriction that can be visualized by electron microscopy (Byers \& Goetsch, 1976). Like other known cytoskeletal proteins, 
such as actin and tubulin, the sequence of all known septins predicts that they may bind phosphonucleotides, namely GTP (Flescher et al., 1993; Longtine et al., 1996; Field \& Kellogg, 1999). Thus, Drosophila septins have been reported to exhibit GTPase activity (Field et al., 1996) and a point mutation neighbouring the putative Ploop GTP-binding domain of S. cerevisiae Cdc10 causes loss of septin function (Cid et al., 1998a). Zhang et al. (1999) have reported that the mammalian septin H5 binds specifically to membrane phosphatidylinositol polyphosphates in a GTP-dependent fashion, suggesting that GTP-binding might account for the association of the septin polymers to their target membranes.

The septin-based ring at the bud neck in yeast has been found to be responsible for crucial events in cellular morphogenesis throughout the mitotic cycle, such as (a) the selection of cell polarity by interaction with the axial pole markers Bud3, Bud4 and Bud10/Axl2 (Chant et al., 1995; Sanders \& Herskowitz, 1996; Halme et al., 1996; Roemer et al., 1996); (b) chitin deposition at the bud neck via interaction with Bni4 and Chs4 (De Marini et al., 1997); (c) a morphogenesis-dependent cell cycle checkpoint which involves protein kinases of the Nim1 family (Barral et al., 1999; Shulewitz et al., 1999; McMillan et al., 1999); and (d) the spatial localization of the septation machinery at cytokinesis (Lippincott \& Li, 1998; Bi et al., 1998; Cid et al., 1998a). In turn, the highly dynamic cortical cytoskeleton, formed by fastmoving patches consisting of actin and a complex network of actin-binding proteins (see Botstein et al., 1997 for a review), is responsible for the direction of polarized secretion that enables bud growth. The data currently available on the function of the actin and septin cytoskeletal structures indicate that their rearrangements throughout the mitotic cycle direct bud emergence, bud growth and cytokinesis. This assumption implies that their dynamics must be accurately regulated by cell cycle controls so that synchronicity between nuclear and cortical events will allow a successful round of cell division.

Indeed, the actin cytoskeleton has been reported to be time-regulated by the turnover of G1 and B cyclins throughout the cell cycle (Lew \& Reed, 1993), leading to the conclusion that, either directly or indirectly, the cellcycle-dependent kinase (CDK) Cdc28 drives actin rearrangements for proper morphogenesis. Since the septin cytoskeleton is an apparently rigid structure that remains at the bud neck throughout the whole budding cycle, it has been recently hypothesized to work as a physical submembrane barrier that compartmentalizes the budding cell into a morphogenetically active daughter side and a morphogenetically inactive mother side (Barral et al., 2000). However, the relationship between septin filaments assembly and maintenance and cell cycle regulatory mechanisms is still poorly understood. In this work we study the cell cycle landmarks that monitor the assembly of the septin ring, its maintenance and its duplication at the end of the cell cycle. We find that septin dynamics are driven by cyclin/CDK-dependent functions and that they are constant under different developmental programmes, such as zygotic bud growth and pseudohyphal differentiation.

\section{METHODS}

Yeast strains, growth media and culture conditions. The strains used in this work are listed in Table 1. FY1679-1a is a segregant from the diploid FY1679 strain. The LAY1 strain was constructed by transforming strain 1783 with PvuIIcleaved pGAL-CLN2 and selecting for recombinant clones. Cells were grown in $250 \mathrm{ml}$ flasks containing $50 \mathrm{ml}$ YED or culture tubes with $5 \mathrm{ml}$ YED $(2 \%, \mathrm{w} / \mathrm{v}$, glucose; $1 \%$, w/v, yeast extract) for general purposes or SD (1.7 g Difco nitrogen base without amino acids $1^{-1} ; 0.5 \%$ ammonium sulphate; $2 \%$ glucose) plus the required mixture of amino acids for plasmid maintenance. YEG medium is YED in which glucose has been replaced by galactose in the same proportion. Solid media were based on the same formula plus $2 \%(\mathrm{w} / \mathrm{v})$ agar. Growth temperatures were $24^{\circ} \mathrm{C}$ for general purposes and $37^{\circ} \mathrm{C}$ for the expression of the phenotype in thermosensitive mutant strains. All yeast genetic techniques were carried out according to standard protocols (Sherman, 1991; Sherman \& Hicks, 1991).

Molecular biology techniques. E. coli transformation and other molecular biology techniques were performed as described by Sambrook et al. (1989). Restriction endonucleases and other enzymes were provided by Boehringer Mannheim. Yeast transformation was achieved by the lithium acetate protocol (Ito et al., 1983). The plasmids used in this work were pLA10 (Cid et al., 1998a), pKGCV12 (kindly provided by J. M. Rodríguez-Pachón), pCT3-H2 (Cid et al., 1998b), YCplac111 (Gietz \& Sugino, 1988), pGAL-CLN2 (kindly provided by L. H. Johnston), pGAL-CLB2 (kindly provided by M. Glotzer) and pUS752 (a TRP1-based plasmid carrying CLB2 $(\mathrm{db} \Delta)$, provided by U. Surana). For the construction of the pLA2 plasmid, a SacI-SacI fragment of pCT3-H2 containing the BEM2 ORF was cloned in the SacI site of the YCplac111 vector. pLA10H was constructed by disrupting the URA3 marker in the pLA10 vector. This was achieved by cleaving the pLA10 vector with $S m a \mathrm{I}$ and ligating into it a PstI-Pst $1.8 \mathrm{~kb}$ fragment containing the HIS3 gene, previously treated with T4 DNA polymerase to generate blunt ends.

Western blotting was performed as follows : $20 \mathrm{ml}$ aliquots of cell culture were placed on ice in a Falcon centrifuge tube and pelleted in a refrigerated centrifuge. Cells were then resuspended in $1 \mathrm{ml}$ ice-cold water and transferred to an Eppendorf tube, pelleted and immediately frozen on dry ice. Cells were broken in $120 \mu \mathrm{l}$ cold lysis buffer $[50 \mathrm{mM}$ Tris $/ \mathrm{HCl}$ (pH 7.5), $10 \%$ glycerol, $1 \%$ Triton X-100, $0 \cdot 1 \%$ SDS, $150 \mathrm{mM}$ $\mathrm{NaCl}, 50 \mathrm{mM} \mathrm{NaF}, 1 \mathrm{mM}$ sodium orthovanadate, $50 \mathrm{mM} \beta$ glycerol phosphate, $5 \mathrm{mM}$ sodium pyrophosphate, $5 \mathrm{mM}$ EDTA, $1 \mathrm{mM}$ PMSF and the protease inhibitors tosylphenylalanine chloromethyl ketone, tosyllysine chloromethyl ketone, leupeptin, pepstatin A, antipain and aprotinin, each at $25 \mu \mathrm{g} \mathrm{ml}^{-1}$ ] by vigorous shaking with $0.45 \mathrm{~mm}$ glass beads in a fast-prep cell breaker (Bio 101; level $5 \cdot 5$ for $25 \mathrm{~s}$ ). Cell extracts were separated from glass beads and cell debris and collected in an Eppendorf tube by centrifugation, then further clarified by a $13000 \mathrm{~g}$ spin for $15 \mathrm{~min}$ at $4{ }^{\circ} \mathrm{C}$. The protein concentration of the supernatants was measured at $280 \mathrm{~nm}$ and normalized with lysis buffer. Then, $2 \times$ SDS-PAGE sample loading buffer was added and samples were boiled for $5 \mathrm{~min}$. Protein samples $(50 \mu \mathrm{g})$ were fractionated by SDS-PAGE using $8 \%$ polyacrylamide gels and transferred to nitrocellulose membranes (Hybond; Amersham). Membranes were probed with anti-Clb2 polyclonal antibodies (kindly provided by D. 
Table 1. Strains used in this work

\begin{tabular}{|c|c|c|}
\hline Strain & Genotype & Reference \\
\hline LAY1 & \multicolumn{2}{|c|}{ MATa leu2-3,112 GAL1-CLN2 (LEU2) trp1-1 ura3-52 his4 can ${ }^{R}$ This work } \\
\hline YJJ21 & MAT $\alpha$ ura3 leu2 cdc13-1 & J. Jimenez (Complutense Univ., Madrid, Spain) \\
\hline V918 & MATa/a bem2-21/bem2-21 ura3/ura3 leu2/leu2 his3 trp1 & Cid et al. (1998b) \\
\hline TB50 $\alpha$ & MAT $\alpha$ ura3 his 3 trp1 leu2 & M. Hall (Biozentrum, Basel, Switzerland) \\
\hline AS171-3a & MAT $\alpha$ ura3 his3 trp1 leu2 sac7::kanMX4 & M. Hall (Biozentrum, Basel, Switzerland) \\
\hline OHNY1 & MATa ura3 his 3 trp1 leu2 ade2 & Yamochi et al. (1994) \\
\hline HNY21 & MATa ura3 his3 trp1 leu2 ade2 rho1-104 & Yamochi et al. (1994) \\
\hline DJTD2-16D & MAT $\alpha$ cdc42-1 ura3 his4 trp1 leu2 gal2 & Johnson \& Pringle (1990) \\
\hline ¿1278b-CGX69 & 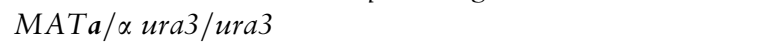 & G. Fink (Whitehead Institute, Massachussets, USA) \\
\hline FY1679-1a & MATa leu2 trp1 his3 ura3 & This work \\
\hline 15DAU & MATa leu 2 ura3 trp1 cdc14-1 & A. Bueno (Salamanca Univ., Spain) \\
\hline K1414 & MATa $c d c 28-4$ ura3-52 leu2-3 ade2-1 & C. Kuhre (Biozentrum, Basel, Switzerland) \\
\hline 1783 & MATa leu2-3,112 trp1-1 ura3-52 bis4 can ${ }^{R}$ & D. Levin (Johns Hopkins Univ., USA) \\
\hline 1784 & MAT a leu2-3,112 trp1-1 ura3-52 bis4 can ${ }^{R}$ & D. Levin (Johns Hopkins Univ., USA) \\
\hline $4965-3 \mathrm{a}$ & MATa cdc16 ura3 leu2 his7 can ${ }^{R}$ & L. Hartwell (Univ. of Washington, Seattle, USA) \\
\hline $4086-23-2 a$ & MATa cdc23 ura3 leu2 his7 & L. Hartwell (Univ. of Washington, Seattle, USA) \\
\hline
\end{tabular}

Kellogg) at $1 / 2000$ dilution in the presence of $5 \%$ non-fat milk for $2 \mathrm{~h}$ at room temperature. The primary antibody was detected using a horseradish peroxidase (HRP)-conjugated anti-rabbit antibody with the ECL detection system.

Confocal and fluorescence microscopy. Thin SD-agar medium layers on slides for time-lapse microscopy were prepared as described previously (Jiménez et al., 1998). Confocal microscopy was performed with an Olympus IMT-2 microscope attached to a Bio-Rad MRC1000 confocal system. The thickness of confocal sections was $1 \mu \mathrm{m}$.

For fluorescence microscopy, cells from exponentially growing cultures were spun, washed once with sterile water and observed. The fluorescence microscope was equipped with a HB-10101AF mercury fluorescent lamp from Nikon. Photographs were taken with a Nikon FX-35A camera and the film used was Ilford 400 ASA. For statistics on cell populations expressing the septin-GFP fusion, a mean of 200 cells were counted for each experiment.

\section{RESULTS}

\section{Cdc10 dynamics are similar throughout budding, zygote development and pseudohyphal growth}

To monitor the septin-based cytoskeletal structure in vivo, we used a protein fusion of the budding yeast septin Cdc10 with the green fluorescent protein (GFP) of Aquorea victoria in the centromeric pLA10 plasmid. This construction expresses the fusion from the original CDC10 promoter and is able to complement a loss-offunction $c d c 10-11$ mutation (Cid et al., 1998a). By introduction of pLA10 in the haploid 1783 strain and analysis of cells under time-lapse confocal microscopy on SD-agar microlayers at room temperature we were able to follow the dynamics of the Cdc10 septin throughout the budding process (Fig. 1a-g). As expected, the fusion protein concentrated at the pre-bud site before bud emergence, at the bud neck throughout all the stages of bud development and as an apparent double structure at the time of cytokinesis. After cytokinesis, the mark faded as a new one appeared adjacent to it, thus marking the new budding site. This timely distribution was identical to that predicted by immunofluorescence on fixed cells for the Cdc3, Cdc11 and Cdc12 septins in the classic work by J. Pringle and coworkers (Ford \& Pringle, 1991; Kim et al., 1991) and to that observed in vivo throughout the cytokinetic stage for a Cdc12-GFP fusion (Lippincott \& Li, 1998), suggesting that the localization of Cdc10 runs parallel to that of the other mitotic septins and that it may serve as a good marker for following the dynamics of the septin cytoskeleton in vivo.

As regards the sexual cycle, Cdc3, Cdc11 and Cdc12 septins have been reported to be present at the base of the mating projection as a rather diffuse ring and then as a tight normal ring at the base of the zygotic bud (Kim et al., 1991; Ford \& Pringle, 1991). Fig. 1(h-o) shows a time-lapse experiment on mating of the 1783 and 1784 isogenic strains of opposite mating type, both transformed with pLA10. The image in Fig. 1(h) shows that Cdc10-GFP is also present at the base of the shmoo and remains there during the fusion process. However, once the site of the emergence of the diploid bud is selected, this mark fades except for a small spot, while a welldefined Cdc10 ring marks the budding site, remaining at the base of the developing zygotic bud throughout the whole budding process. As can be seen in Fig. 1(m) and $(\mathrm{n})$, cytokinesis in zygotes is also supported by a double septin ring and, after this process has been completed, a new ring is formed adjacent to the previous one. It can be concluded from these observations that the septin cytoskeleton in budding zygotes behaves in an analogous fashion to bud development during vegetative growth.

Saccharomyces cerevisiae diploid strains are susceptible to undergoing pseudohyphal growth when starved for nitrogen in solid medium, displaying a growth pattern 

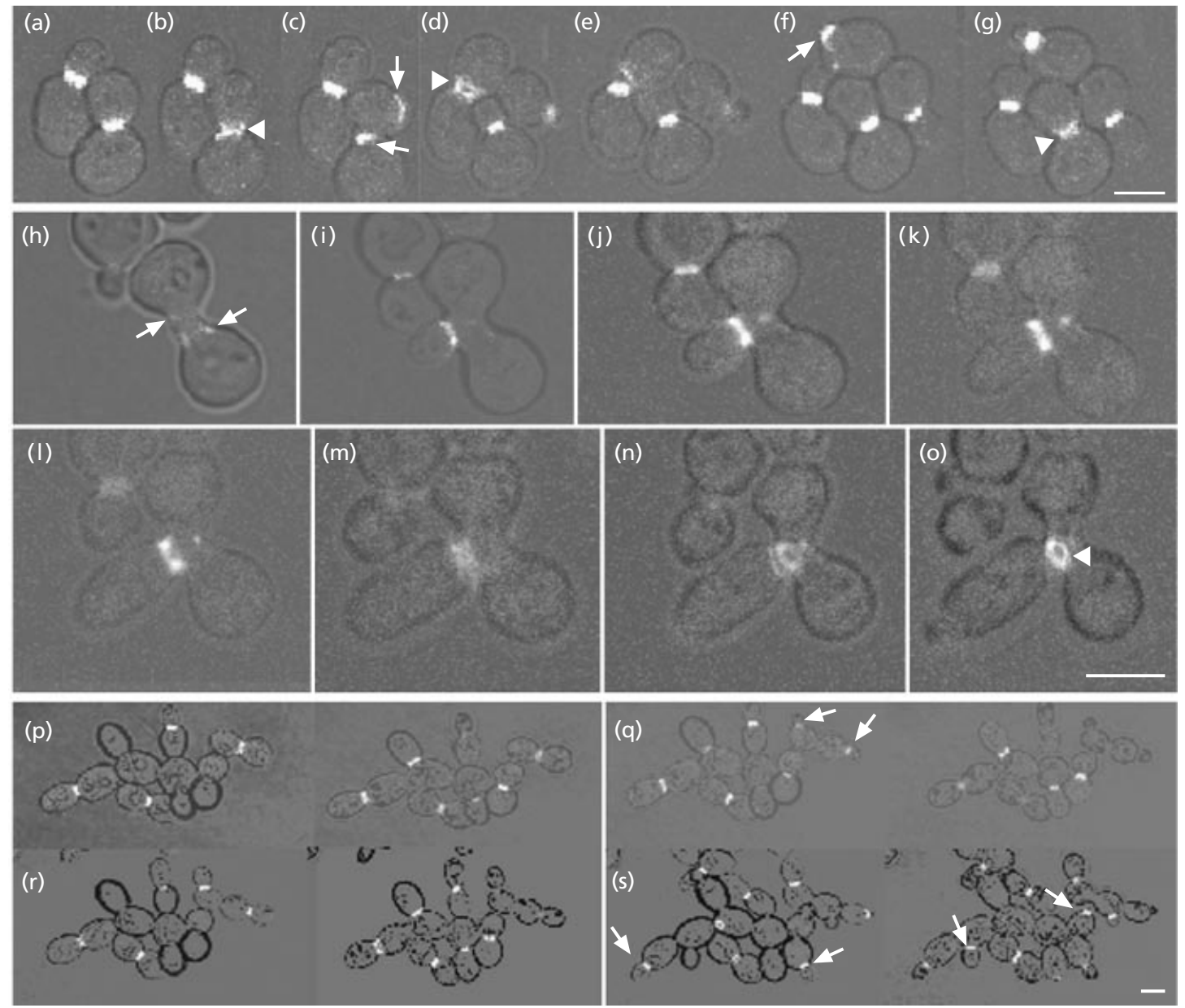

Fig. 1. Time-lapse confocal microscopy of cells expressing a Cdc10-GFP fusion during vegetative growth (a-g), zygote development $(h-o)$ and pseudohyphal growth $(p-s)$. (a-g) Series of images of two budding cells from strain 1783 transformed with pLA10 (CDC10-GFP), taken every $20 \mathrm{~min}$. Arrows indicate the appearance of a newly assembled ring. Arrowheads indicate double cytokinetic septin rings. ( $h-0)$ Series showing the process of zygotic bud development after mating pLA10 transformants from the 1783 (MATa) and 1784 (MAT $\alpha)$ strains. Images were taken every 20 min except for the step from (h) to (i), which corresponds to an interval of 40 min. Cdc10-GFP diffusely marks the neck of mating shmoos (arrow). Newly assembled rings are indicated by arrowheads. (p-s) Series of images of $\Sigma 1278 b-C G X 69$ pLA10 transformants growing in low-nitrogen medium SLADH. Images were taken within an interval of $1 \mathrm{~h}$. The two images in each part correspond to two different confocal planes of the same field, separated by $2 \mu \mathrm{m}$. Arrows indicate newly assembled rings in synchronously growing buds from mothers no longer showing septins at their previous cytokinetic sites. Bars, $5 \mu \mathrm{m}$.

that diverges from that of budding yeast cells (Kron et al., 1994). Yeast growth obeys a bipolar pattern of polarity and is asynchronous, that is mother and daughter cells do not start a new round of budding at the same time due to the fact that cell separation takes place when the daughter has not achieved its maximum size. Cells in pseudohyphae, however, divide synchronously and in a unipolar fashion, probably to facilitate colonization of the medium. A diploid strain on a $\Sigma 1278$ b background was transformed with pLA10 and examined by time-lapse confocal microscopy for Cdc10GFP localization in low-nitrogen SLADH agar microlayers. The results of this experiment, shown in Fig. $1(\mathrm{p}-\mathrm{s})$, revealed that synchronous unipolar growth is also supported by a septin ring that follows a basic dynamic pattern indistinguishable from that observed during the budding of individual yeast cells grown in rich medium.

\section{The START landmark of the cell cycle is essential for septin ring assembly}

Reorganizations of cytoskeletal structures that participate in morphogenesis, such as the actin cortical patches, are triggered by cell-cycle-dependent signals (Lew \& Reed, 1993). The association or dissociation of the yeast main CDK, namely Cdc28, with either G1 (Cln) or mitotic (Clb) cyclins seem to accurately control actin rearrangements throughout the cell cycle (Lew \& Reed, 1995). It has been shown that actin polarization to the pre-bud site depends on the START landmark of the cell cycle, characterized by the appearance of Cln-Cdc28 


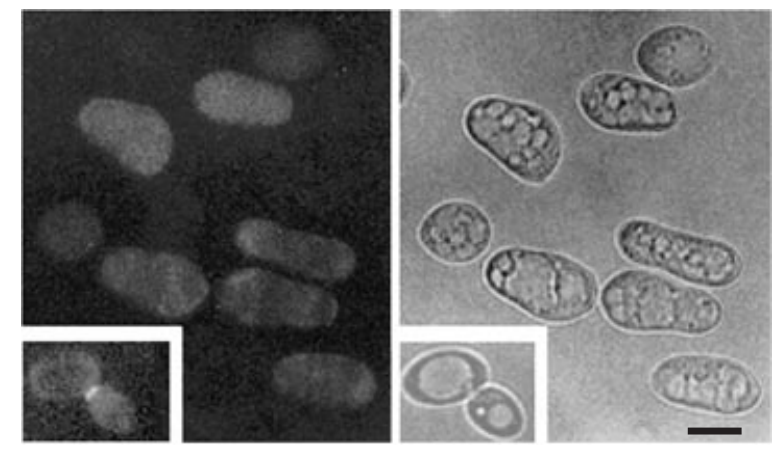

Fig. 2. Analysis by fluorescence microscopy of START-defective K1414 transformants (cdc28-4) bearing the pLA10 (CDC10-GFP) plasmid. Fluorescence (left) and phase-contrast (right) microscopy images of the same fields, showing the lack of assembled septin structures at $37^{\circ} \mathrm{C}$. The cell in the inset in each panel corresponds to the same strain at $24^{\circ} \mathrm{C}$. Bar, $5 \mu \mathrm{m}$.

complexes (Lew \& Reed, 1993). We wished to know whether the appearance of the septin ring at the incipient bud site might also depend on such CDK-dependent signals. If so, $c d c 28-4$ mutant strains, which bear a thermosensitive START-defective specific allele of the yeast CDK, should fail to assemble the septin ring. As shown in Fig. 2, Cdc10-GFP was correctly localized at the permissive temperature in strain K1414 (more than $90 \%$ of the cells showed assembled rings), but could not be detected after the culture was switched to $37^{\circ} \mathrm{C}$ for $2 \mathrm{~h}$ (more than $90 \%$ of the population lacked rings). Statistically, $88 \%$ of the cells were budded at $24{ }^{\circ} \mathrm{C}$ and, within the unbudded population, $69 \%$ bore septin rings, whereas after the switch to $37^{\circ} \mathrm{C} 92 \%$ of the cellular population lacked buds, none of them displaying localized Cdc10-GFP $(n=200)$. This is not due to loss of GFP fluorescence at high temperatures, since the Cdc10-GFP fusion can be readily observed in cells grown at $37^{\circ} \mathrm{C}$ (Cid et al., 1998a; see below). We observed that the morphogenetic effects of the $c d c 28-4$ mutation were dependent on the strain background. In genetic backgrounds different from that of the K1414 strain, derived from crosses of this strain with different wild-type strains, cells occasionally tended to elongate and Cdc10-GFP marks were often detected, although they constituted fairly aberrant structures rather than proper rings (data not shown). Altogether, these data suggest that septin assembly is dependent on a functional G1 cyclin/Cdc28 complex.

\section{Cdc42, but not Rho1, are key determinants for septin ring assembly at the bud site}

The Cdc42 small GTPase is essential for bud site assembly (reviewed by Cabib et al., 1998; Johnson, 1999), presumably in response to Cdc28/G1 cyclindependent signals. Most characterized $c d c 42$ loss-offunction alleles originate round unbudded multinucleated cells at the restrictive temperature. We introduced the septin-GFP construction in the DJTD2-16D strain, bearing a $c d c 42-1 \mathrm{ts}^{-}$mutation. Although at
$24{ }^{\circ} \mathrm{C} 92 \%$ of the population displayed assembled septin ring-like structures (Fig. 3a), these were not neat but often discontinuous (Fig. 3b), suggesting that a partial dysfunction of Cdc42 may alter septin assembly. However, at the non-permissive temperature, large round cells were produced, showing a more dramatic defect in the localization of Cdc10. Only about $6 \%$ of the population bore any visible septin structure (Fig. 3a) and, when present, such structures were very seldom ring-shaped, but rather looked like dots, patches or, rarely, bars (Fig. 3c and d).

The above data prove that loss of Cdc42 function precludes septin assembly. At this point we decided to investigate the effect of a constitutive activation of this GTPase. For this purpose, we took advantage of a GAL1-based overexpression plasmid bearing a constitutively activated $c d c 42^{\mathrm{V} 12}$ allele (pKGCV12). To simultaneously express $c d c 42^{\mathrm{V} 12}$ and Cdc10-GFP in the cell, we developed a HIS3-based vector bearing the CDC10-GFP fusion, named pLA10H. We introduced both plasmids in the wild-type FY1679-1a strain and studied Cdc10 localization both in glucose- and galactose-based media. Peculiarly, transformants growing in galactose gave rise to a subpopulation (ranging from 20 to $30 \%$ ) of highly amorphous cells that either lacked septin structures or showed abnormal Cdc10GFP patches (Fig. 3e). Even in non-aberrant cells, patchlike structures instead of rings were frequently observed (data not shown), a phenomenon that was never observed when the same transformants were grown in glucose (Fig. 3a). In summary, both loss of function and hyperactivation of the Rho-like GTPase Cdc42 have negative effects in the integrity of the septin cytoskeleton.

Rho1 is another small GTPase that plays a key role in the regulation of morphogenesis (Drgonová et al., 1996; Qadota et al., 1996; see Cabib et al., 1998 for a review), promoting actin-based polarized secretion and cell wall glucan synthesis. We transformed the strains HNY21 (rho1-104) and OHNY1 (isogenic wild-type control) with the pLA10 plasmid to study septin distribution under the expression of the $\mathrm{ts}^{-}$rho1 mutation. As shown in Fig. 4(a) and (b), after incubation at $37^{\circ} \mathrm{C}$ for $2 \mathrm{~h}$, wild-type cells showed the expected proportion of cells displaying 'single', 'neck-spanning' and 'separated' septin rings. Single rings appeared in unbudded or small-budded cells, whereas in medium- or large-budded cells, the Cdc10-GFP mark extended around the base of both mother and daughter cells as an hourglass-like neck-spanning ring. Separated parallel rings occurred only in large-budded cells (see Fig. 4a for an illustration of these three types of cells). rho1 mutant cells arrested with a small incipient bud that was encircled by a single Cdc10-GFP ring (Fig. $4 \mathrm{a}$ and b).

Bem 2 and Sac7 are thought to act as GTPase-activating proteins (GAPs) and are, thus, negative regulatory elements for Rho1 (Peterson et al., 1994; Schmidt et al., 1997; Martín et al., 2000). The localization of Cdc10GFP in the AS171-3a strain (sac7::kanMX4) was indistinguishable from that of the isogenic wild-type strain TB50 $\alpha$ (data not shown). However, in a bem2-21 
(a)
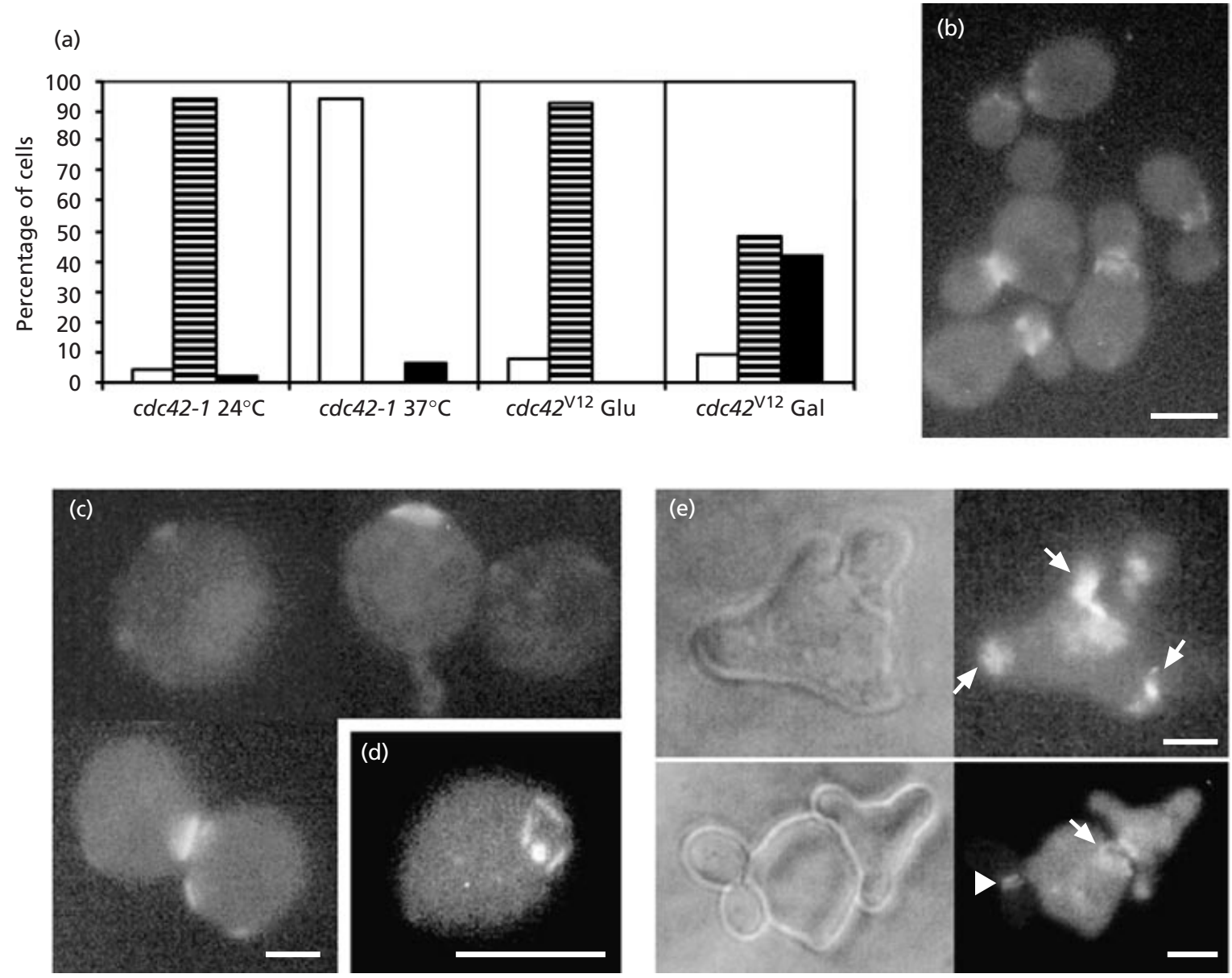

Fig. 3. Effect of the $c d c 42-1$ mutation and $C d c 42^{\mathrm{V} 12}$ overexpression on the localization of Cdc10-GFP. (a) Statistics of populations of cdc42-1 mutants at the permissive and restrictive temperatures and cells expressing $\mathrm{Cdc}_{\mathrm{C}} \mathrm{2}^{\mathrm{V} 12}$ under the control of the GAL1 promoter under both repressing and inducing conditions. The percentage of cells of each type (lacking septin structures, $\square$; displaying normal septin rings, 目; or showing septin patches, $\square$ ) is represented on the $y$ axis. The expression of the thermosensitive cdc42-1 mutation clearly precludes septin ring formation, while the induction of $\mathrm{Cdc} 42^{\mathrm{V} 12}$ leads to an increased population of cells showing abnormal septin structures. (b) Fluorescence microscopy of cdc42-1 mutant cells expressing Cdc10-GFP at the permissive temperature of $24^{\circ} \mathrm{C}$. Some septin rings look loose even in these conditions. (c) Fluorescence microscopy of the few cdc42-1 mutant cells showing Cdc10-GFP structures at the restrictive temperature of $37^{\circ} \mathrm{C}$. Most of the rare structures detected in these conditions are not rings but patches. (d) A cell in identical conditions to those in (c), displaying an abnormal ring-like structure constituted by a spot and three bars of Cdc10-GFP. (e) FY1679-1a cells expressing both Cdc42 ${ }^{\mathrm{V} 12}$ and Cdc10-GFP under phase-contrast and fluorescence microscopy. The highly amorphous cells generated lack properly assembled septin rings, often showing patches adjacent to abortive bud necks (arrows). The arrowhead points to a normal cytokinetic septin ring for comparison. Bars, $5 \mu \mathrm{m}$.

mutant (V918 strain), which displays a phenotype of large multinucleate cells, pleiotropic defects in Cdc10GFP distribution were observed. As a control we used the same strain bearing both the pLA10 and a BEM2containing pLA2 plasmid. Common alterations on septin distribution observed in bem2-21 mutants were large and/or thick rings, discontinuous ring-like structures, cells with more than one bud supported by a septin ring at the same time (Fig. 4c) and the presence of separated cytokinetic septin rings in small-budded cells (data not shown). The overall data indicate that, unlike Cdc42, the Rho1 small GTPase is not essential for the assembly and shaping of the septin cytoskeleton, but rather for subsequent events that lead to polarized secretion for the promotion of bud emergence. However, the deregulation of Rho1 seems to alter the coordination of morphogenesis throughout the cell cycle, involving an abnormal behaviour of the septin cytoskeleton.

\section{Septin ring integrity is unaffected by either G2 or M cell cycle arrests}

Deregulation of the expression of G1 cyclins affects morphogenesis by altering the dynamics of the actin cytoskeleton (Lew \& Reed, 1993). At this point we wished to study the effect of the overexpression of Cln2 (a G1 cyclin) in the septin cytoskeleton. With this aim, we constructed strain LAY1, bearing a GAL1-CLN2 cassette integrated in its genome. Incubation of this strain in galactose led to partial cell elongation as a 

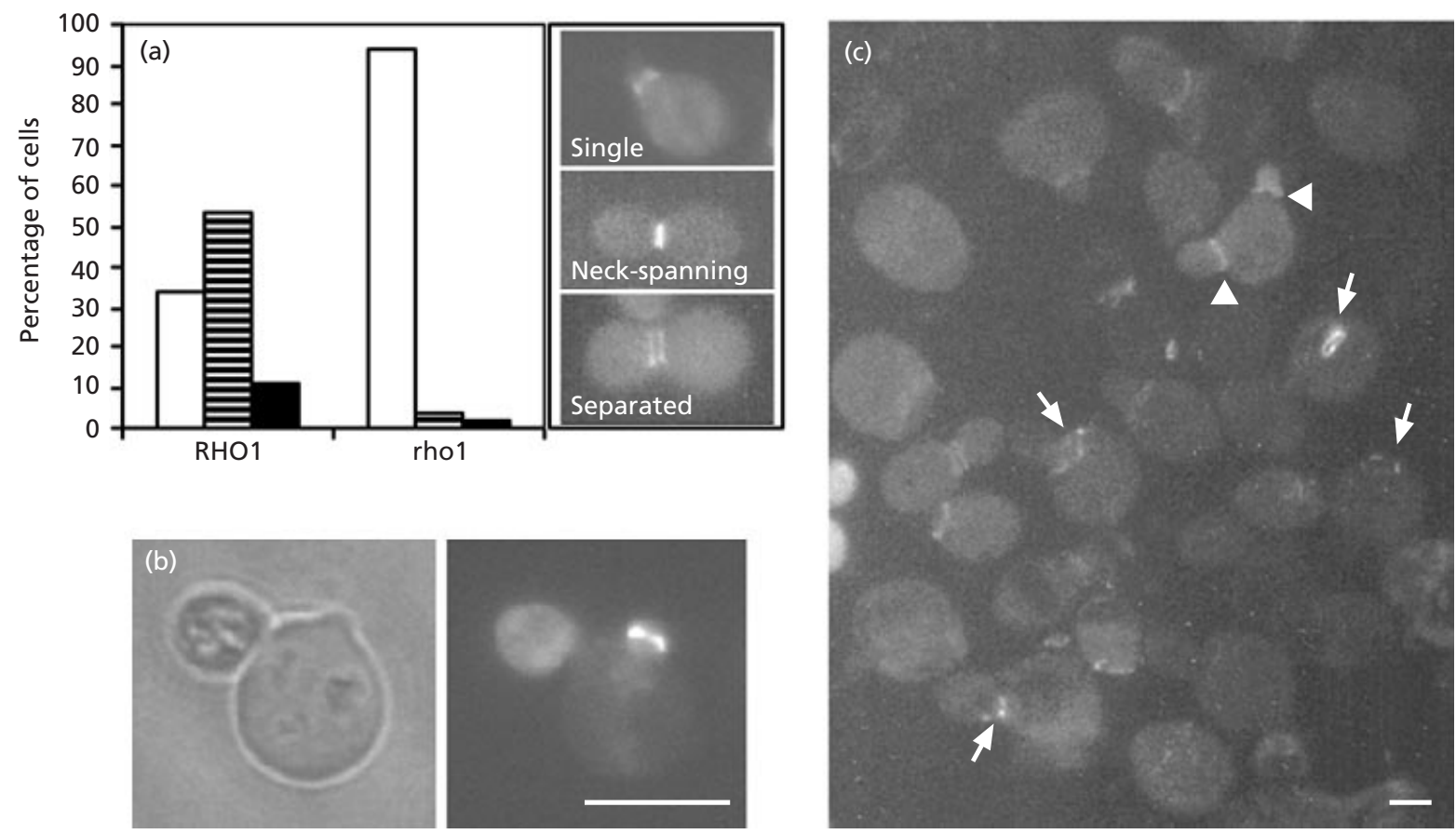

Fig. 4. Effect of rho1-104 and bem2-21 mutations in the localization of Cdc10-GFP. (a) The percentage of cells in cultures of OHNY1 (wild-type) and HNY21 (rho1-104) strains, grown at $37^{\circ} \mathrm{C}$, showing single ( $\square$ ), neck-spanning (目) or separated septin rings ( $\square$ ) (see the images in the inset, taken from cycling wild-type FY1679-1a cells expressing CDC10-GFP from pLA10, as a visual reference). A dysfunction in Rho1 elicits an accumulation of cells with a single septin ring. (b) A characteristic cell from HNY21 expressing the rho1-104 mutation at $37^{\circ} \mathrm{C}$. The Cdc10-GFP fusion accumulates at the base of the characteristic small aborted buds. (c) A culture of V918 (bem2-21) cells expressing Cdc10-GFP. Discontinuous, aberrant or misplaced rings are often observed (arrows), as well as strange septin localization patterns such as cells maintaining two small buds, each of them supported by a basal septin ring (arrowheads). Bars, $5 \mu \mathrm{m}$.

morphogenetic response to a delay in the entry into $\mathrm{M}$ phase. This effect was not very dramatic since a single copy of the overexpression cassette would not be expected to cause a serious delay of the cell cycle (Lew \& Reed, 1993). In general, in spite of the morphological alteration, septins were properly located under these conditions (Fig. 5e). Only a careful statistical study of the cell population revealed that the proportion of cells displaying a single ring was slightly higher in galactose than in glucose medium, in detriment to the population with neck-spanning or separated neck rings (Fig. 5a). This observation probably reflects a partial accumulation of cells in late G1. A more drastic pre-mitotic arrest can be achieved by activation of the DNA-damage cell cycle checkpoint (see Longhese et al., 1998 for a review). The checkpoint mechanism is activated by failures during DNA replication, which are thought to induce an inactivation of the Cdc28-Clb kinase until the mistake is corrected, thus subordinating mitosis to prior essential events in the cell cycle. We analysed septin-GFP distribution in the YJJ21 strain, which bears a mutation in the $c d c 13$ gene that encodes a telomere-binding protein whose dysfunction causes the activation of the DNA-damage/repair checkpoint (Nugent et al., 1996). Incubation of the mutant at the non-permissive temperature led to homogeneous arrest of the cells as doublets with a continuous neck-spanning septin ring (Fig. 5b and f).
Nocodazole added to yeast cultures interferes with microtubule assembly, leading to mitotic arrest in anaphase as a consequence of the activation of a second cell cycle checkpoint that monitors spindle assembly (Wang \& Burke, 1995; Straight \& Murray, 1997). Haploid and diploid S. cerevisiae strains FY1679-1a and $\Sigma 1278$ b-CGX69 were transformed with the pLA10 plasmid, arrested with nocodazole and analysed for Cdc10-GFP localization. As shown in Fig. 5(c) and (g) for strain FY1679-1a, the characteristic arrested largebudded cells also displayed a continuous neck-spanning ring. This effect was more readily observable in the diploid $\Sigma 1278$ b background (data not shown). We also investigated the localization of the septin-GFP fusion in strains defective in components of the anaphase-promoting complex (APC). Populations of pLA10 transformants of strains $4965-3 \mathrm{a}$ (bearing a $c d c 16^{\text {ts }}$ allele) were analysed under fluorescence microscopy, yielding the results shown in Fig. 5(d). Very similar results were obtained in the same kind of analysis on the $c d c 23^{\text {ts }}$ mutant strain 4086-23-2a (data not shown). In both cases, cells arrested as doublets with clear hourglassshaped septin rings. Since the bud continues to grow to a maximum size both in $c d c 13$ mutants and APC mutants or nocodazole-treated cells, despite the respective G2 and anaphase arrests, it is likely that the development and maintenance of a symmetric neckspanning septin structure runs parallel to the process of 

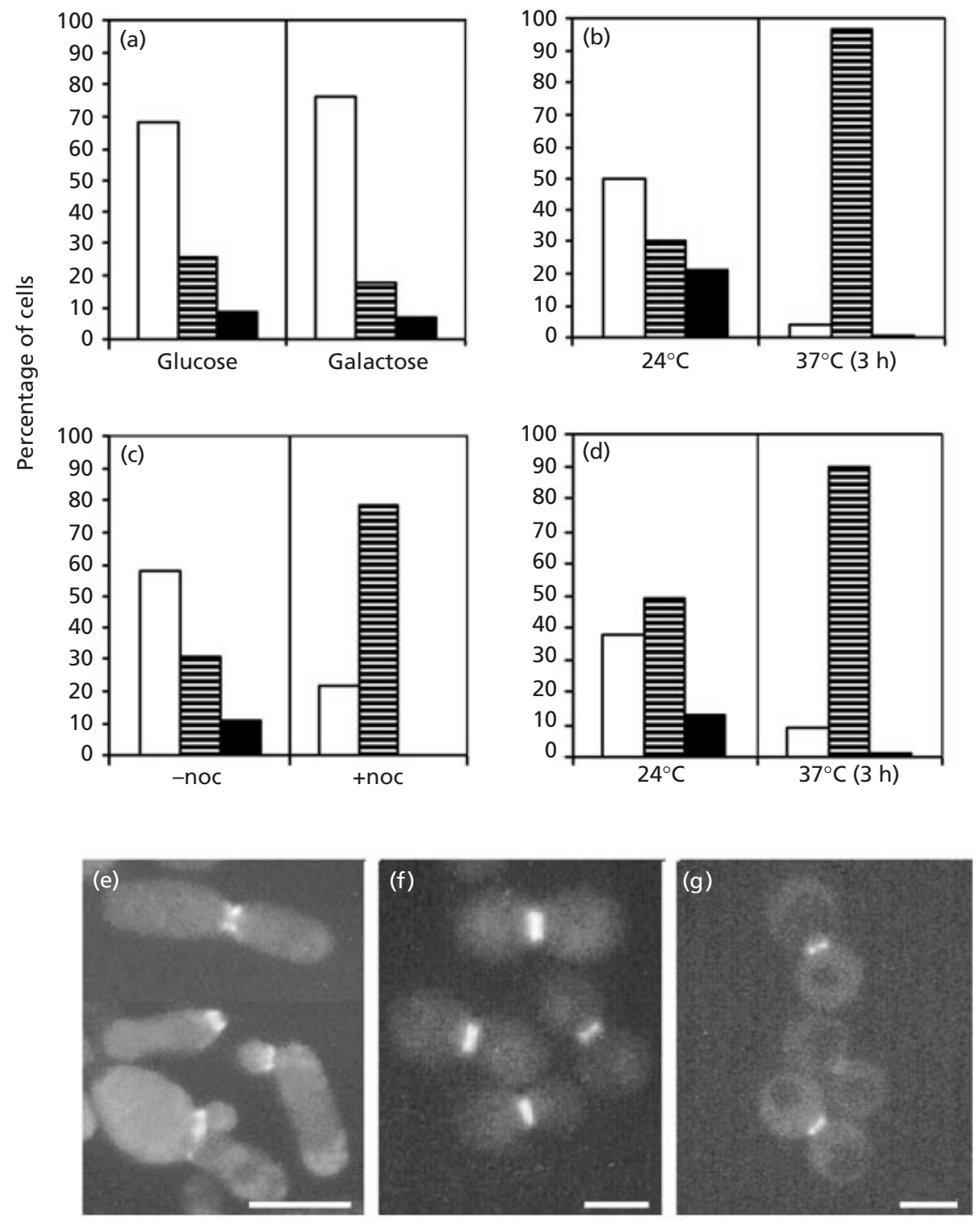

Fig. 5. Studies on Cdc10-GFP localization, when overexpressing $\mathrm{Cln} 2$, inducing a cdc13-dependent cell-cycle arrest, arresting a culture with nocodazole or in a cdc16-induced arrest. (a) Statistics of LAY1 (GAL-CLN2) pLA10 (CDC10-GFP) transformants showing single $(\square)$, neck-spanning (目) or separated septin rings ( $\square$ ) (see Fig. 4a for a visual reference of these cell types). The population of cells with a single ring is slightly enhanced when CLN2 is overexpressed from a GAL1 promoter. (b) The same statistics of cells in a thermosensitive cdc13 mutant at 24 or $37^{\circ} \mathrm{C}$. Expression of the cdc13 phenotype arrests the cells with a symmetric but not separated ring. (c) The same statistics of FY1679-1a cells expressing Cdc10-GFP grown in the absence $(-n o c)$ or presence $(+$ noc) of the microtubule-destabilizing drug nocodazole. (d) The same statistics of a 4965-3a (cdc16 ts ${ }^{-}$) strain. (e) Fluorescence image of LAY1 cells transformed with pLA10H growing in galactose. Cells overexpressing CLN2 tend to elongate, but the localization of Cdc10 is maintained at the bud neck. (f) Fluorescence image of pLA10-transformed cdc13 mutant cells incubated at $37^{\circ} \mathrm{C}$. (g) Fluorescence image of the nocodazole-arrested FY1679-1a haploid strain expressing Cdc10-GFP. Bars, $5 \mu \mathrm{m}$.

bud growth, which seems to be independent of nuclear events at this stage.

\section{Septin ring separation at cytokinesis depends on the function of late mitotic regulators}

We simultaneously introduced the pLA10H and the pGAL1-CLB2 plasmids in the FY1679-1a strain to study the influence of B cyclin overexpression in Cdc10-GFP dynamics. As depicted in the graph in Fig. 6(a), incubation of the transformants in galactose led to the accumulation of cells with a continuous neck-spanning septin ring, probably as a consequence of the elongation of the $M$ phase. The expression of a non-degradable version of the cyclin, CLB2(dbA) (Surana et al., 1993), under its own promoter led to a similar pattern (data not 

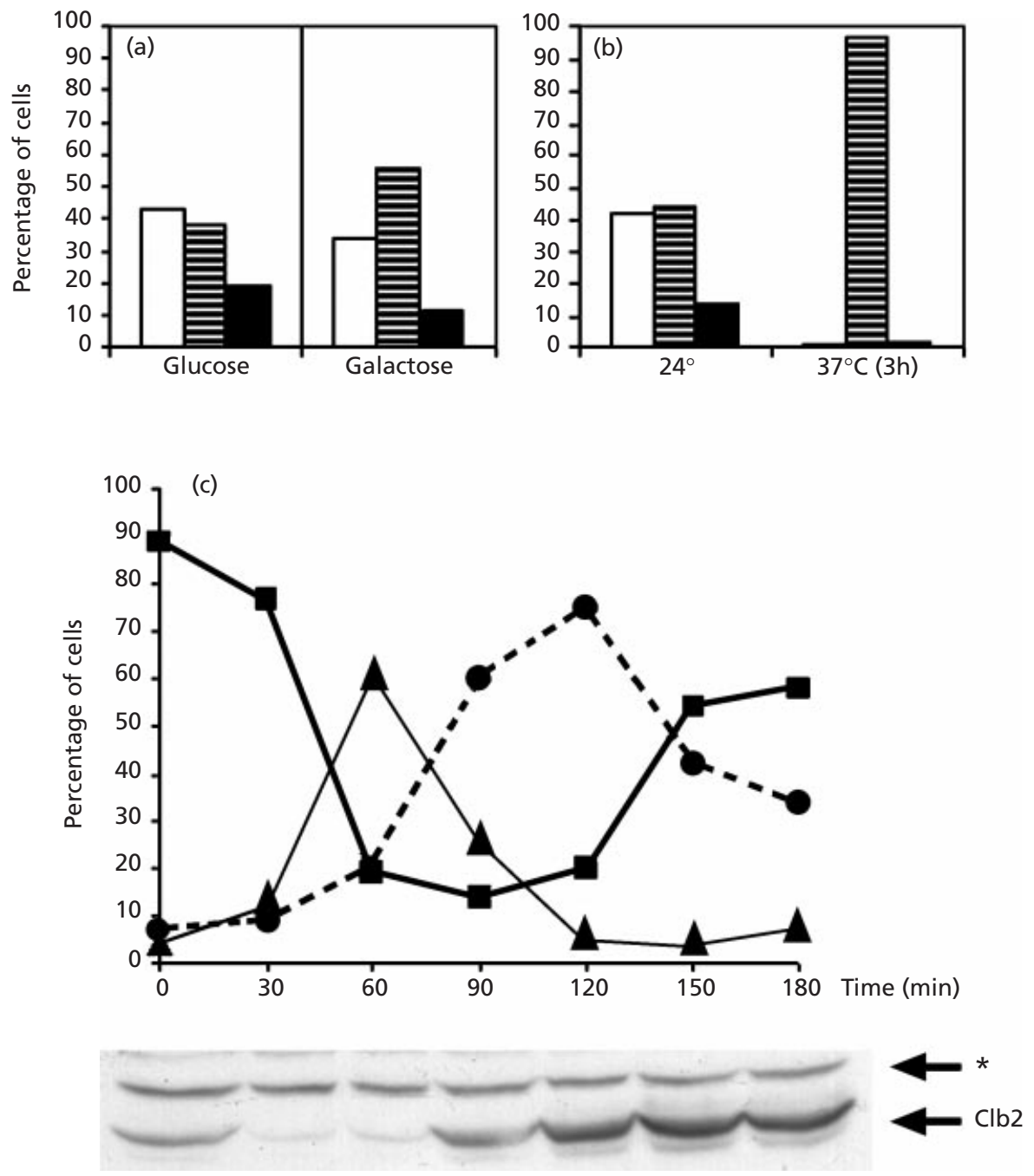

Fig. 6. Effect of CLB2 overexpression (a) and a thermosensitive $c d c 14$ mutation (b, c) on the distribution of populations of cells with a single $(\square)$, neck-spanning (目) or separated septin ring ( $\square$ ) (see Fig. 4a for a visual reference of these cell types), as detected by microscopic observation of Cdc10-GFP. (c) Evolution of the same cell populations with a single (0), neck-spanning ( $\boldsymbol{\square}$ ) or separated septin ring $(\boldsymbol{\Delta})$ when a culture is released from a cdc14-induced arrest in fresh medium at permissive temperature. The percentage of cells of each category is represented on the $y$ axis. A Western blot using anti-Clb2 antibodies performed with samples taken at the same intervals is shown below the graph. *The non-specific band cross-reacting with $\mathrm{Clb} 2$ antiserum serves as a loading control.

shown). Cdc15 is a protein kinase essential for the exit from mitosis, arresting cells in late anaphase (Schweitzer \& Philippsen, 1991; Surana et al., 1993). In a previous study, we reported that $c d c 15$ mutants were unable to septate and to reassemble septins at new sites of polarized growth (Jiménez et al., 1998). A side observation was that $c d c 15$-arrested mutants, like $c d c 13$ $c d c 16-c d c 23-$ or nocodazole-arrested cells, were not able to give rise to the double clearly separated septin ring that is characteristic of the cytokinetic stage. The same phenomenon was observed in cdc14-1 mutants (Fig. 6b) defective in a protein phosphatase that plays an essential role in mitotic exit (Shou et al., 1999; Visintin et al., 1999), as determined after transformation of the 15DAU strain with pLA10 and analysis of Cdc10-GFP distribution at $37^{\circ} \mathrm{C}$.
Since failures in either the CDC14 or CDC15 genes originate the maintenance of high $\mathrm{B}$ cyclin levels, it has been proposed that their ultimate role could be the activation of the proteosomal apparatus for the specific degradation of Clb1 and Clb2 (Jaspersen et al., 1998). This suggests that $\mathrm{Clb}$ removal might be the signal that causes the symmetrical septin structure to eventually split into two twin rings at the cytokinetic stage. To further investigate this point, we studied the evolution of Cdc10 dynamics in $c d c 14-1$ cells recovering from the mitotic arrest. Cells that had been kept for $2 \mathrm{~h}$ at $37^{\circ} \mathrm{C}$ were transferred to fresh medium and incubated at $24{ }^{\circ} \mathrm{C}$. Samples were taken every $30 \mathrm{~min}$ and the distribution of cells with single, neck-spanning (continuous) and neatly separated (discontinuous) rings was determined. As shown in Fig. 6(c), 60 min after the 
switch to the permissive temperature virtually the entire population consisted of cell doublets with conspicuously separated rings. At this time cells have overcome the mitotic arrest, displaying low Clb levels. Similar results were obtained when the same experiment was performed in $c d c 16$ and $c d c 23$ mutants (data not shown). However, if cells were maintained for several hours at the restrictive temperature, the non-separated ring tended to grow thicker, covering a wider area around the neck in both mother and daughter cells (data not shown). In summary, our data point to the idea that the formation of the double cytokinetic septin ring depends on the activity of the mitotic exit network and that the persistence of $\mathrm{B}$ cyclins in the cell prevents the ring from splitting.

\section{DISCUSSION}

\section{The signals that control septin assembly and disassembly}

Cell division involves rapid cytoskeletal rearrangements that direct the dynamics of nuclear division, organellar segregation, cell surface growth and cytokinesis. In the budding yeast, the tubulin-based cytoskeleton is known to drive nuclear dynamics while the actin cytoskeleton is mainly responsible for the direction of polarized secretion to growing areas. Both cytoskeletal structures have been reported to be highly dynamic (Waddle et al., 1996; Shaw et al., 1997). Previous studies demonstrated that septins, a third putative cytoskeletal structure which seems to play a crucial role in the control of cell division, localized exclusively encircling the bud neck throughout the whole cycle, from bud emergence to cytokinesis (Haarer \& Pringle, 1987; Ford \& Pringle, 1991; Kim et al., 1991). Thus, according to current knowledge, septins constitute a structure that is far less dynamic than those based on actin or tubulin. However, here we report that at least the two crucial steps in the development of the septin neck ring, assembly at the G1 phase and separation at late mitosis, are dependent on cell cycle signalling. Furthermore, our results on septin dynamics in alternative developmental processes, such as budding zygotes and pseudohyphal growth, indicate that the pattern of septin assembly, maintenance at the neck during bud growth and duplication at cytokinesis is general to all budding events in yeast. Interestingly, novel findings point to the idea that the septin ring at the bud neck is polarized: first, components of a signalling pathway that negatively regulates Swe1, an inhibitor of the mitotic Cdc28 protein kinase, localize specifically to the septin ring side that faces the daughter cell (Barral et al., 1999; Shulewitz et al., 1999); and second, at the stage of mitosis septins have been reported to be covalently bound to SUMO, a ubiquitin-like protein, specifically located at the mother cell side of the neck (Johnson \& Blobel, 1999). Polarization of the septin neck structure would involve a complex spatial regulation that we are only beginning to understand, but these novel data hint that the septin scaffold might likely prove to be more dynamic at the molecular level than it seems to be under fluorescence microscopy.
Fig. 7 summarizes the hypotheses suggested by the results in this work. Although it is not shown in Fig. 7 to avoid complication, in cells growing exponentially the disappearance of the septin ring remaining from the previous cytokinesis site usually overlaps in time with the assembly of the new ring at an adjacent spot (see Fig. $1 \mathrm{f}$, in which both old and new rings co-exist at a certain stage). In a previous report (Jiménez et al., 1998) we showed that in late mitotic mutants $(c d c 14, c d c 15$, etc.) cytokinetic-defective cells can rebud but they cannot remove septins from the aborted cytokinesis site. This observation suggests that the disassembly of the septin ring relies on signals left by the cytokinetic machinery. The total lack of assembled septin structures in $c d c 28-4$ mutants indicates that the disassembly of septins at the previous cytokinetic site does not depend on the function of G1 cyclin-Cdc28 kinase. At the same time, this indicates that septin assembly to the selected bud site is dependent on such activity. Our observation that both the loss of function and the expression of constitutively activated $\mathrm{Cdc} 42$ alter septin distribution indicates that this small GTPase plays a role in directing the proper assembly of this structure. The facts that Cla4, a protein kinase from the PAK family that interacts with Cdc42, is important for proper bud neck assembly (Cvrcková et al., 1995) and that certain mutant alleles of Cdc42 display a behaviour similar to that of cla4 mutants (Richman et al., 1999) suggest that Cla4 may be a mediator in Cdc42 function in the co-ordination of septin ring formation. We also show that the Rho1 GTPase plays its essential role in bud emergence once septins are properly assembled, further supporting the notion that Rho1 functions in a stage downstream of Cdc42, as proposed by Chant (1994). As a consequence, the function of Rho1 is not essential for septin assembly. However, the aberrant septin distribution that we observed in mutants in the putative Rho1-GAP bem2 suggests that hyperactive Rho1 may cause discoordination of morphogenetic events throughout cell division, leading to general perturbations in cytoskeletal dynamics. Still, the role of Bem 2 in morphogenesis could be something other than its regulation of Rho1, as suggested by the pleiotropic bem 2 phenotype. In spite of their occasionally altered thickness, shape or localization, septin rings are assembled at the bud site in bem 2 mutants, reinforcing the idea that Rho1-dependent signals play no role in septin assembly.

\section{Septin dynamics throughout mitosis}

Apparently, the septin ring does not suffer dramatic changes during the process of bud growth in the G2 and $M$ phases. However, careful analysis of ring morphology as the bud grew revealed that the compact circular structure assembled at the time of bud emergence gradually turns into a symmetric neck-spanning shape that covers both sides of the neck in budded cells. Since we are currently unaware of the actual distribution of septin filaments in the bud neck, we cannot discern whether this behaviour would involve structural rearrangements or whether it merely reflects the adap- 


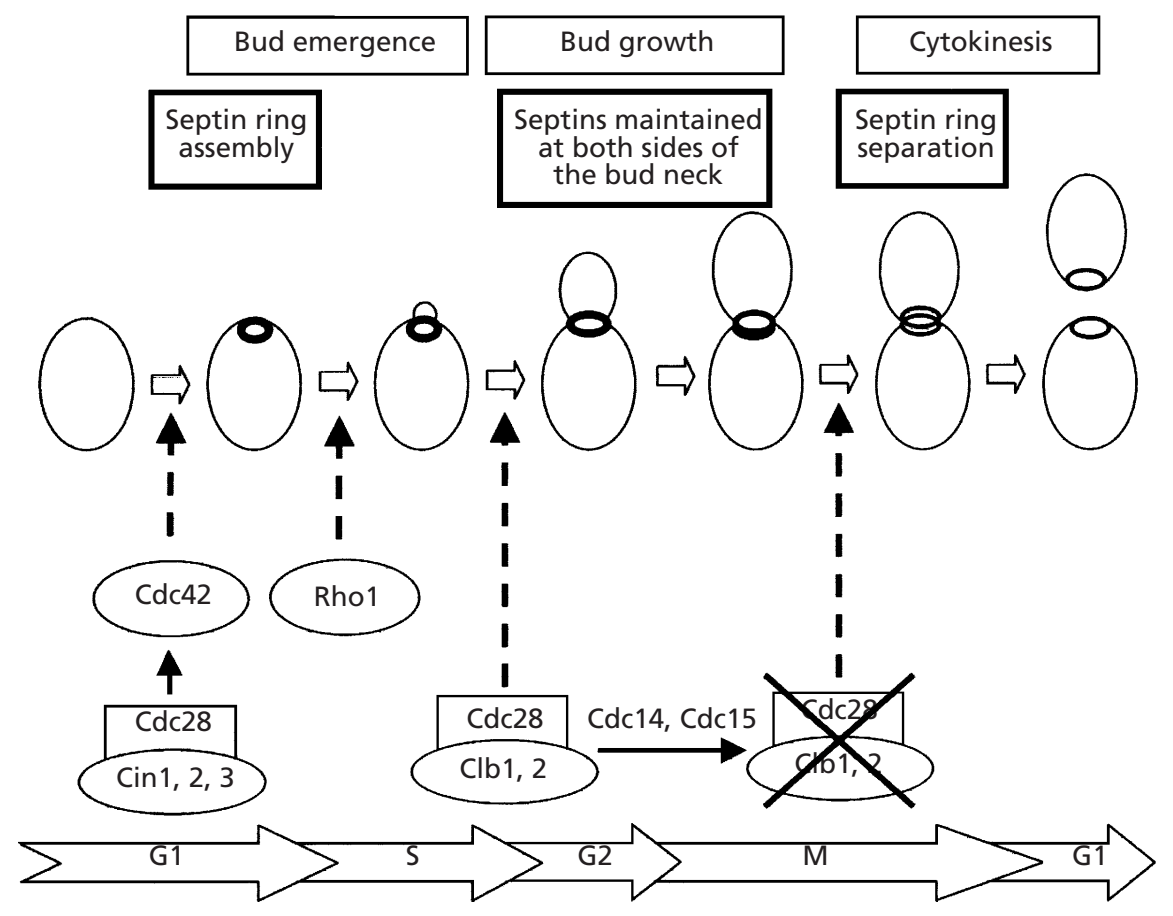

Fig. 7. Scheme of the dynamics of septin rings throughout budding and the cell cycle regulatory events that govern them. Septin ring assembly at the pre-bud site is triggered by signalling dependent on G1 cyclin-CDK (Cdc28) and the small GTPase Cdc42 plays a key role in mediating this event. Rho1 is essential for the proper establishment of bud emergence at a stage subsequent to septin assembly at the pre-bud neck. During bud growth throughout S, G2 and M phases of the cell cycle, the septin ring gradually expands to conform the neck-spanning structure that covers both mother and daughter sides of the constriction, appearing under fluorescence microscopy as the hourglass-shaped ring that is characteristic of metaphase- and anaphase-arrested cells. These stages coincide in cell cycle timing with the establishment and maintenance of isotropic bud growth. At the time of cytokinesis, and as a result of the activation of the Cdc14- and Cdc15-dependent mitotic exit network, which in turn triggers B cyclin degradation by the proteasome, the neck-spanning ring finally splits into two symmetric conspicuously separated structures that stand at both sides of the septation plane. After cytokinesis, old septin rings will fade as the cell gets ready for a new round of the cell cycle.

tability of a relatively plastic structure to the dynamics of the growing bud neck.

We show here that the eventual separation of these rings depends on the onset of the molecular mechanisms that trigger exit from mitosis, namely B cyclin removal. We base this conclusion on the fact that $c d c 14$ and $c d c 15$ mutants, as well as APC ( $c d c 16$ and $c d c 23)$ mutants, are essential for the splitting of the septin ring into two parallel structures and that this phenomenon occurs simultaneously with Clb2 destruction. The observation that long incubation times at the non-permissive temperature of $c d c 14, c d c 15, c d c 16$ or $c d c 23$ mutants result in overspread neck-spanning septin structures suggests that the active $\mathrm{Cdc} 28-\mathrm{B}$ cyclin complex participates in septin ring expansion towards both sides of the neck. As suggested by the predominance of the same double-sided rings in either nocodazole- or $c d c 13$-arrested cells, the cell cycle checkpoints that respond to spindle disassembly and DNA damage, respectively, do not influence the development of the septin cytoskeleton at this stage. This is not surprising in nocodazole-arrested cells, since damage of the spindle or its motor structures is known to cause cell cycle arrest in anaphase, apparently at the same morphogenetic stage as muta- tions in APC components. However, activation of the DNA-damage cell cycle checkpoint by mutations in $c d c 13$ is known to arrest the cell cycle earlier, namely at the G2/M transition (Garvik et al., 1995). Although the cell does not undergo nuclear mitosis in $c d c 13$ mutants, bud growth persists and the septin cytoskeleton evolves to the same stage as nocodazole- or even $c d c 14$-arrested cells. One way of understanding this is that the signal that determines isotropic bud growth commits the daughter cell to reach its maximum size regardless of nuclear events. This hypothesis would assume that the formation and maintenance of a symmetric neckspanning septin structure is a consequence of the endowment of isotropic bud growth. In summary, the co-ordination of morphogenesis throughout the cell cycle might rely on three essential landmarks, as postulated by Lew \& Reed (1995): bud emergence, promoted by G1 cyclins; the switch from polar to isotropic growth, determined by $\mathrm{B}$ cyclins; and cytokinesis, triggered by the degradation of $\mathrm{B}$ cyclins. In parallel, we propose that the same sequence of oscillations in cyclin levels would determine, respectively, the assembly of the septin ring, its development into a symmetric structure and finally its separation into two distinct parallel rings. 


\section{The role of septins in the control of morphogenesis during cell division}

The role of the septin cytoskeleton in defining the pattern of polarity has been postulated on the basis that septin mutants lose cell polarity and that bud site selection markers, such as Bud3, Bud4 and Bud10, colocalize with septins (Flescher et al., 1993; Chant et al., 1995; Sanders \& Herskowitz, 1996; Halme et al., 1996; Roemer et al., 1996). Once the bud site is chosen, the combined functions of the actin and septin cytoskeletal structures seem to direct bud emergence and growth. At the time of bud emergence, actin and septin coincide at the budding site, but actin cortical patches move to the growing tip as the bud emerges, while septins remain unaltered at the base of the bud. An interesting view for understanding morphogenesis at this stage would be to consider the assembled septin ring as the border of the morphogenetically active site at the cell surface. Although this view has proven to be applicable to later stages of the cell cycle, during bud development (Barral et al., 2000; Takizawa et al., 2000), it fails to ring true at the initial stage, since bud emergence, regardless of polarity, is properly achieved in septin mutants (Hartwell, 1971). Assuming that the septin cytoskeleton is dispensable for bud emergence, why does Cdc42 recruit septins at the pre-bud site at that particular stage of cell cycle? According to the phenotype of septin mutants, which leads to hyperpolarized bud growth, the septin cytoskeleton is essential for the transition from polar to isotropic bud growth, a process that relies on the activation of Clb-Cdc28 complexes (Lew \& Reed, 1993). In fact, septin-associated components of signal transduction pathways have been recently associated with Swe1-dependent activation of Cdc28 (Barral et al., 1999; Shulewitz et al., 1999; McMillan et al., 1999), defining a morphogenesisdependent cell cycle checkpoint. A sensible hypothesis is that septins would be laid at the bud site to participate in bud-emergence-dependent signals that activate the checkpoint pathways for dephosphorylation and activation of $\mathrm{B}$ cyclin-Cdc28, which in turn promotes isotropic bud growth by means of yet unknown mechanisms.

The other stage of the cell cycle in which septins play a crucial role is cytokinesis. Our previous results suggested that the septation mechanisms are not blocked in septin mutants, but the spatial landmark to localize such mechanisms is lost (Cid et al., 1998a). Although septin mutants are unable to form septa properly, septins do not seem to be components of the contractile structure assembled at the time of septation, but submembrane marks for its proper localization. Rather than contracting at the cytokinetic stage, the septin hourglassshaped structure splits into two differentiated rings. It has been demonstrated that an actomyosin contractile ring is located in between both septin rings at that stage (Lippincott \& Li, 1998; Bi et al., 1998). This observation further suggests that the role of the septin cytoskeleton is to locate the cytokinetic machinery at the proper plane. Further research on septin-interacting com- ponents and the combined dynamics of both the septin and actin cytoskeletal scaffolds should shed light on the important issue of cell-cycle-dependent regulation of morphogenesis. In this sense, the yeast model can be expected to reveal important clues for the developmental behaviour of higher eukaryotic cells.

\section{ACKNOWLEDGEMENTS}

We thank Alberto Álvarez for confocal microscopy and J. M. Rodriguez-Pachón, J. Jiménez, H. Martín, M. Hall, A. Bueno, D. Kellogg, M. Shulewitz, J. Thorner, Y. Takai, D. Levin, L. H. Johnston, M. Glotzer, R. Padmashree, U. Surana and G. Fink for plasmids, strains and antibodies. Lubica Adamiková was supported by a grant from the Ministerio de Asuntos Exteriores, Spain, and the research was supported by a grant from the CICYT (BIO98-0726) and another grant from the FIS (97/0047-01).

\section{REFERENCES}

Barral, Y., Parra, M., Bidlingmaier, S. \& Snyder, M. (1999). Nim1related kinases coordinate cell cycle progression with the organization of the peripheral cytoskeleton in yeast. Genes Dev 13, 176-187.

Barral, Y., Mermall, V., Mooseker, M. S. \& Snyder, M. (2000). Compartmentalization of the cell cortex by septins is required for maintenance of cell polarity in yeast. Mol Cell 5, 841-851.

Beites, C. L., Xie, H., Bowser, R. \& Trimble, W. S. (1999). The septin CDCrel-1 binds syntaxin and inhibits exocytosis. Nat Neurosci 5, 434-439.

Bi, E., Maddox, P., Lew, D. J., Salmon, E. D., McMillan, J. N., Yeh, E. \& Pringle, J. R. (1998). Involvement of an actomyosin contractile ring in Saccharomyces cerevisiae cytokinesis. J Cell Biol 142, 1301-1312.

Botstein, D., Amberg, D., Mulholland, J., Huffaker, T., Adams, A., Drubin, D. \& Stearns, T. (1997). The yeast cytoskeleton. In The Molecular and Cellular Biology of the Yeast Saccharomyces cerevisiae, pp. 1-90. Edited by J. R. Pringle, J. R. Broach \& E. W. Jones. Cold Spring Harbor, NY : Cold Spring Harbor Laboratory.

Byers, B. \& Goetsch, L. (1976). A highly ordered ring of membraneassociated filaments in budding yeast. J Cell Biol 69, 717-721.

Cabib, E., Drgonová, J. \& Drgon, T. (1998). Role of small G proteins in yeast cell polarization and wall biosynthesis. Annu Rev Biochem 67, 307-333.

Carroll, C. W., Altman, R., Schieltz, D., Yates, J. R. \& Kellogg, D. (1998). The septins are required for the mitosis-specific activation of the Gin4 kinase. J Cell Biol 143, 709-717.

Chant, J. (1994). Cell polarity in yeast. Trends Genet 10, 328-333.

Chant, J., Mischke, M., Mitchell, E., Herskowitz, I. \& Pringle, J. R. (1995). Role of Bud3p in producing the axial budding pattern of yeast. J Cell Biol 129, 767-778.

Cid, V. J., Adamiková, L., Cenamor, R., Molina, M., Sánchez, M. \& Nombela, C. (1998a). Cell integrity and morphogenesis in a budding yeast septin mutant. Microbiology 144, 3463-3474.

Cid, V. J., Cenamor, R., Sánchez, M. \& Nombela, C. (1998b). A mutation in the Rho1-GAP-encoding gene BEM2 of Saccharomyces cerevisiae affects morphogenesis and cell wall functionality. Microbiology 144, 25-36.

Curcková, F., De Virgilio, C., Manser, E., Pringle, J. R. \& Nasmyth, K. (1995). Ste20-like protein kinases are required for normal localisation of cell growth and for cytokinesis in budding yeast. Genes Dev 9, 1817-1830. 
De Marini, D. J., Adams, A. E. M., Fares, H., DeVirgilio, C., Valle, G., Chuang, J. S. \& Pringle, J. R. (1997). A septin-based hierarchy of proteins required for localised deposition of chitin in Saccharomyces cerevisiae cell wall. J Cell Biol 139, 75-93.

De Virgilio, C., De Marini, D. J. \& Pringle, J. R. (1996). SPR28, a sixth member of the septin gene family in Saccharomyces cerevisiae that is expressed specifically in sporulating cells. Microbiology 142, 2897-2905.

Drgonová, J., Drgon, T., Tanaka, K., Kollar, R., Chen, G. C., Ford, R. A., Chan, C. S., Takai, Y. \& Cabib, E. (1996). Rho1p, a yeast protein at the interface between cell polarization and morphogenesis. Science 272, 277-279.

Fares, H., Peifer, M. \& Pringle, J. R. (1995). Localisation and possible functions of Drosophila septins. Mol Biol Cell 6, 1843-1859.

Fares, H., Goetsch, L. \& Pringle, J. R. (1996). Identification of a developmentally regulated septin and involvement of the septins in spore formation in Saccharomyces cerevisiae. J Cell Biol 132, 399-411.

Field, C. M. \& Kellogg, D. (1999). Septins: cytoskeletal polymers or signalling GTPases? Trends Cell Biol 10, 387-394.

Field, C. M., al-Awar, O., Rosenblatt, J., Wong, M. L., Alberts, B. \& Mitchison, T. J. (1996). A purified Drosophila septin complex forms filaments and exhibits GTPase activity. J Cell Biol 133, 605-616.

Flescher, E. G., Madden, K. \& Snyder, M. (1993). Components required for cytokinesis are important for bud site selection in yeast. J Cell Biol 122, 373-386.

Ford, S. K. \& Pringle, J. R. (1991). Cellular morphogenesis in the Saccharomyces cerevisiae cell cycle: localisation of the CDC11 gene product and the timing of events at the budding site. Dev Genet 12, 281-292.

Frazier, J. A., Wong, M. L., Longtine, M. S., Pringle, J. R., Mann, M., Mitchison, T. J. \& Field, C. (1998). Polymerization of purified yeast septins: evidence that organized filament arrays may not be required for septin function. J Cell Biol 143, 737-749.

Garvik, B., Carson, M. \& Hartwell, L. (1995). Single-stranded DNA arising at telomeres in $c d c 13$ mutants may constitute a specific signal for the RAD9 checkpoint. Mol Cell Biol 15, 6128-6138.

Gietz, R. D. \& Sugino, A. (1988). New yeast-Escherichia coli shuttle vectors constructed with in vitro mutagenized yeast genes lacking six-base pair restriction sites. Gene 74, 527-534.

Haarer, B. \& Pringle, J. R. (1987). Immunofluorescence localisation of the Saccharomyces cerevisiae CDC12 gene product to the vicinity of the $10 \mathrm{~nm}$ filaments in the mother-bud neck. Mol Cell Biol 7, 3678-3687.

Halme, A., Michelitch, M., Mitchell, E. L. \& Chant, J. (1996). Bud10p directs axial cell polarization in budding yeast and resembles a transmembrane receptor. Curr Biol 6, 570-579.

Hartwell, L. H. (1971). Genetic control of cell division cycle in yeast. IV. Genes controlling bud emergence and cytokinesis. Exp Cell Res 69, 265-276.

Hartwell, L. H., Culotti, J., Pringle, J. R. \& Reid, B. J. (1974). Genetic control of the cell division cycle in yeast. Science 246, 629-634.

Ito, H., Fukada, Y., Murata, K. \& Kimura, A. (1983). Transformation of intact yeast with alkali cations. J Bacteriol 153, 163-168.

Jaspersen, S. L., Charles, J. F., Tinker-Kulberg, R. L. \& Morgan, D. O. (1998). A late mitotic regulatory network controlling cyclin destruction in Saccharomyces cerevisiae. Mol Biol Cell 9, 2803-2817.
Jiménez, J., Cid, V. J., Cenamor, R., Yuste, M., Molero, G., Nombela, C. \& Sanchez, M. (1998). Morphogenesis beyond cytokinetic arrest in Saccharomyces cerevisiae. J Cell Biol 143, 1617-1634.

Johnson, D. I. (1999). Cdc42: an essential Rho-type GTPase controlling eukaryotic cell polarity. Microbiol Mol Biol Rev 63, 54-105.

Johnson, D. I. \& Pringle, J. R. (1990). Molecular characterization of CDC42, a Saccharomyces cerevisiae gene involved in the development of cell polarity. J Cell Biol 111, 143-152.

Johnson, E. S. \& Blobel, G. (1999). Cell cycle-regulated attachment of the ubiquitin-related protein SUMO to the yeast septins. J Cell Biol 147, 981-993.

Kim, H. B., Haarer, B. K. \& Pringle, J. R. (1991). Cellular morphogenesis in the Saccharomyces cerevisiae cell cycle: localisation of the $C D C 3$ gene product and the timing of events at the budding site. J Cell Biol 112, 535-544.

Kinoshita, M., Kumar, S., Mizoguchi, A., Ide, C., Kinoshita, A., Haraguchi, T., Hiraoka, Y. \& Noda, M. (1997). Nedd5, a mammalian septin, is a novel cytoskeletal component interacting with actin-based structures. Genes Dev 11, 1535-1547.

Kron, S. J., Styles, C. A. \& Fink, G. R. (1994). Symmetric cell division in pseudohyphae of the yeast Saccharomyces cerevisiae. Mol Biol Cell 5, 1003-1022.

Lew, D. J. \& Reed, S. I. (1993). Morphogenesis in the yeast cell cycle: regulation by Cdc28 and cyclins. J Cell Biol 120, 1305-1320. Lew, D. J. \& Reed, S. I. (1995). Cell cycle control of morphogenesis in the budding yeast. Curr Opin Genet Dev 5, 17-23.

Lippincott, J. \& Li, R. (1998). Sequential assembly of myosin II, an IQGAP-like protein, and filamentous actin to a ring structure involved in budding yeast cytokinesis. J Cell Biol 140, 355-366.

Longhese, M. P., Foiani, M., Muzi-Falconi, M., Lucchini, G. \& Plevani, P. (1998). DNA damage checkpoint in budding yeast. EMBO J 17, 5525-5528.

Longtine, S. M., de Marini, D. J., Valencik, M. L., Al-Awar, O. S., Fares, H., De Virgilio, C. \& Pringle, J. R. (1996). The septins: roles in cytokinesis and other processes. Curr Opin Cell Biol 8, 106-119.

McMillan, J. N., Longtine, M. S., Sia, R. A., Theesfeld, C. L., Bardes, E. S., Pringle, J. R. \& Lew, D. J. (1999). The morphogenesis checkpoint in Saccharomyces cerevisiae: cell cycle control of Swe1p degradation by Hsl1p and Hsl7p. Mol Cell Biol 10, 6929-6939.

Martín, H., Rodríguez-Pachón, J. M., Ruiz, C., Nombela, C. \& Molina, M. (2000). Regulatory mechanisms for modulation of signaling through the cell integrity Slt2-mediated pathway in Saccharomyces cerevisiae. J Biol Chem 275, 1511-1519.

Mino, A., Tanaka, K., Kamei, T., Umikawa, M., Fujiwara, T. \& Takai, Y. (1998). Shs1p: a novel member of the septin that interacts with Spa2p, involved in polarized growth in Saccharomyces cerevisiae. Biochem Biophys Res Commun 251, 732-736.

Neufeld, T. P. \& Rubin, G. M. (1994). The Drosophila peanut gene is required for cytokinesis and encodes a protein similar to yeast putative bud neck filament proteins. Cell 77, 371-379.

Nugent, C. I., Hughes, T. R., Lue, N. F. \& Lundblad, V. (1996). Cdc13p: a single-strand telomeric DNA-binding protein with a dual role in yeast telomere maintenance. Science 274, 249-252.

Peterson, J., Zheng, Y., Bender, L., Myers, A., Cerione, R. \& Bender, A. (1994). Interactions between the bud emergence proteins Bem1p and Bem2p and Rho-type GTPases in yeast. J Cell Biol 127, 1395-1406.

Qadota, H., Python, C. P., Inoue, S. B., Arisawa, M., Anraku, Y., 
Zheng, Y., Watanabe, T., Levin, D. E. \& Ohya, Y. (1996). Identification of yeast Rho1p GTPase as a regulatory subunit of 1,3-beta-glucan synthase. Science 272, 279-281.

Richman, T. J., Sawyer, M. M. \& Johnson, D. I. (1999). The Cdc42p GTPase is involved in a G2/M morphogenetic checkpoint regulating the apical-isotropic switch and nuclear division in yeast. J Biol Chem 274, 16861-16870.

Roemer, T., Madden, K., Chang, J. \& Snyder, M. (1996). Selection of axial growth sites in yeast requires Axl2p, a novel plasma membrane glycoprotein. Genes Dev 10, 777-793.

Sambrook, J., Fritsch, E. F. \& Maniatis, T. (1989). Molecular Cloning: a Laboratory Manual, 2nd edn. Cold Spring Harbor, NY : Cold Spring Harbor Laboratory.

Sanders, S. L. \& Herskowitz, I. (1996). The Bud4p protein of yeast, required for axial budding, is localised to the mother/bud neck in a cell cycle-dependent manner. J Cell Biol 134, 413-427.

Schmidt, A., Bickle, M., Beck, T. \& Hall, M. N. (1997). The yeast phosphatidylinositol kinase homolog TOR2 activates RHO1 and RHO2 via the exchange factor ROM2. Cell 88, 531-542.

Schweitzer, B. \& Philippsen, P. (1991). CDC15, an essential cell cycle gene in Saccharomyces cerevisiae, encodes a protein kinase domain. Yeast 3, 265-273.

Shaw, S. L., Yeh, E., Maddox, P., Salmon, E. D. \& Bloom, K. (1997). Astral microtubule dynamics in yeast: a microtubule-based searching mechanism for spindle orientation and nuclear migration into the bud. J Cell Biol 139, 985-994.

Sherman, F. (1991). Getting started with yeast. Methods Enzymol 194, 3-21.

Sherman, F. \& Hicks, J. (1991). Micromanipulation and dissection of asci. Methods Enzymol 194, 21-37.

Shou, W., Seol, J. H., Shevchenko, A. \& 7 other authors (1999). Exit from mitosis is triggered by Tem1-dependent release of the protein phosphatase Cdc14 from nucleolar RENT complex. Cell 97, 233-244.

Shulewitz, M. J., Inouye, C. J. \& Thorner, J. (1999). Hsl7 localises to the septin ring and serves as an adapter in a regulatory pathway that relieves tyrosine phosphorylation of the Cdc28 protein kinase in Saccharomyces cerevisiae. Mol Cell Biol 10, 7123-7137.

Slater, M. L., Bowers, B. \& Cabib, E. (1985). Formation of septumlike structures at locations remote from the budding sites in cytokinesis-defective mutants of Saccharomyces cerevisiae. I Bacteriol 162, 763-767.

Straight, A. F. \& Murray, A. W. (1997). The spindle assembly checkpoint in budding yeast. Methods Enzymol 283, 425-440.

Surana, U., Amon, A., Dowzer, C., McGrew, J., Byers, B. \& Nasmyth, K. (1993). Destruction of yeast CDC28/CLB mitotic kinase is not required for the metaphase to anaphase transition in budding yeast. EMBO J 12, 1969-1978.

Takizawa, P. A., DeRisi, J. L., Wilhelm, J. E. \& Vale, R. D. (2000). Plasma membrane compartmentalization in yeast by messenger RNA transport and a septin diffusion barrier. Science 290, 341-344.

Visintin, R., Hwang, E. S. \& Amon, A. (1999). Cfi1 prevents premature exit from mitosis by anchoring Cdc14 phosphatase in the nucleolus. Nature 398, 818-823.

Waddle, J. A., Karpova, T. S., Waterston, R. H. \& Cooper, J. A. (1996). Movement of cortical actin patches in yeast. J Cell Biol 132, 861-870.

Wang, Y. \& Burke, D. J. (1995). Checkpoint genes required to delay cell division in response to nocodazole respond to impaired kinetochore function in the yeast Saccharomyces cerevisiae. Mol Cell Biol 12, 6838-6844.

Yamochi, W., Tanaka, K., Nonaka, H., Maeda, A., Musha, T. \& Takai, Y. (1994). Growth site localisation of Rho1 small GTPbinding protein and its involvement in bud formation in Saccharomyces cerevisiae. J Cell Biol 125, 1077-1093.

Zhang, J., Kong, C., Xie, H., McPherson, P. S., Grinstein, S. \& Trimble, W. S. (1999). Phosphatidylinositol polyphosphate binding to the mammalian septin H5 is modulated by GTP. Curr Biol 9, 1458-1467.

Received 25 October 2000; revised 19 February 2001; accepted 26 February 2001. 